This item was submitted to Loughborough's Research Repository by the author.

Items in Figshare are protected by copyright, with all rights reserved, unless otherwise indicated.

\title{
Body dissatisfaction and disordered eating in trans people: a systematic review of the literature
}

PLEASE CITE THE PUBLISHED VERSION

http://dx.doi.org/10.3109/09540261.2015.1089217

\section{PUBLISHER}

(c) Taylor \& Francis

\section{VERSION}

AM (Accepted Manuscript)

\section{PUBLISHER STATEMENT}

This work is made available according to the conditions of the Creative Commons Attribution-NonCommercialNoDerivatives 4.0 International (CC BY-NC-ND 4.0) licence. Full details of this licence are available at: https://creativecommons.org/licenses/by-nc-nd/4.0/

\section{LICENCE}

CC BY-NC-ND 4.0

\section{REPOSITORY RECORD}

Jones, Beth, Emma Haycraft, Sarah Murjan, and Jon Arcelus. 2019. "Body Dissatisfaction and Disordered Eating in Trans People: A Systematic Review of the Literature”. figshare. https://hdl.handle.net/2134/20067. 
Body dissatisfaction and disordered eating in trans people 1

\section{Body dissatisfaction and disordered eating in trans people:}

\section{A systematic review of the literature}

Bethany Alice Jones ${ }^{1,2}$, Emma Haycraft ${ }^{2}$, Sarah Murjan ${ }^{1}$, and Jon Arcelus ${ }^{1,2}$

${ }^{1}$ Nottingham Centre for Gender Dysphoria, Nottingham, United Kingdom

${ }^{2}$ School of Sport, Exercise, and Health Sciences, Loughborough University, United Kingdom

Corresponding author: Prof. Jon Arcelus, Nottingham Centre for Gender Dysphoria, 3 Oxford Street, Nottingham, United Kingdom. Tel: 0115 8760160. E-mail:

Jon.Arcelus@nottingham.ac.uk

Running head: Body dissatisfaction and disordered eating in trans people 


\begin{abstract}
Body dissatisfaction plays a prominent role in gender dysphoria. Body dissatisfaction, in some individuals, appears to manifest disordered eating in order to supress bodily features of natal gender and accentuate features of gender identity. To date, there has been no systematic review of the literature pertaining to body dissatisfaction and disordered eating in trans individuals. Such a review may highlight important implications for clinicians working with trans people. Therefore, the aim was to critically and systematically review the available literature examining body dissatisfaction or disordered eating in a trans population, and also the literature pertaining to how body dissatisfaction and disordered eating are related in trans people. This review found three studies that explored disordered eating in trans people, five studies that explored body image and disordered eating in trans people, and 18 studies that explored body image in trans people. The findings from this review suggest that body dissatisfaction is core to the distress trans people experience and that this dissatisfaction may also put some individuals at risk of developing disordered eating. Additionally, the findings appear to suggest that gender dysphoria treatment is successful at increasing body satisfaction and improving body image. The clinical implications are discussed.
\end{abstract}

Keywords: Gender Dysphoria, Trans, Disordered Eating, Body Image, Systematic Review 
Body dissatisfaction and disordered eating in trans people 3

\section{Body dissatisfaction and disordered eating in trans people: A systematic review of the literature}

The Diagnostic and Statistical Manual of Mental Disorders, Fifth Edition (American Psychiatric Association, 2013; DSM-5) classifies the incongruence that trans individuals experience between their assigned sex at birth (and the associated gender role and/or primary and secondary sex characteristic) and gender identity (how they see themselves with respect to gender) as Gender Dysphoria. Transsexualism is defined by the International Classification of Diseases, edition 10 (ICD-10; World Health Organization, 1992) as a desire to live and be accepted as a member of the opposite sex, usually accompanied by a sense of discomfort with, or inappropriateness of, one's anatomic sex, and a wish to have surgery and hormonal treatment to make one's body as congruent as possible with one's preferred sex. The new edition, ICD-11, is expected to acknowledge individuals who do not necessarily wish to transition from one binary gender to the other (male to female or female to male). Although there are several different terms used within the literature to describe people who feel an incongruence between their assigned sex at birth and gender identity, throughout this article the terms 'trans people/individuals', 'trans women' and 'trans men' will be used. Trans women are those who were assigned male at birth on the basis of genital appearance but who later identify themselves as female. Trans men are those who were assigned female at birth based on their genital appearance but identify as male. Recent studies have reported an overall meta-analytical prevalence for transsexualism of 4.6 in 100,000 individuals; 6.8 for trans women and 2.6 for trans men, which is primarily based on studies looking at individuals attending clinical services (Arcelus et al., 2015).

Body dissatisfaction is referred to as the negative evaluation of one's appearance and it is central to the distress and unhappiness that trans individuals experience (Bandini et al., 2013). It is not surprising that this distress is particularly related to body parts that are a reminder of the individual's unwanted assigned sex (e.g., Becker et al., 2015). Much of the research in the area of gender dysphoria and body image has focused on sex-specific body parts which may be transformed by Cross-sex Hormone Treatment (CHT) and surgical treatment. Several studies have found that such treatment is capable of relieving body dissatisfaction (e.g., De Vries, Steensma, Doreleijers, \& Cohen-Kettenis, 2011; De Vries et al., 2014).

Body dissatisfaction is also thought to be central to the distress experienced by those with an eating disorder (e.g., Fairburn, 2008) and it has been shown to be one of the main 
contributors towards the onset and maintenance of eating psychopathology (Stice \& Shaw, 2002). Within the trans literature, Ålgars, Alanko, Santtila, and Sandnabba (2012) discuss the role of eating restriction in trans women as a way to strive for thinness in order to suppress features of their birth sex or to accentuate features of their desired gender. In addition, trans women may internalise the message portrayed by the western media that thin is beautiful (Witcomb et al., 2015). The internalisation of this message is thought to be a risk factor for the development of disordered eating in cisgender (non-trans) women (Kroon Van Diest \& Perez, 2013; Witcomb, Arcelus, \& Chen, 2013) and therefore it may put trans women at a particular risk for developing disordered eating (e.g., Ålgars, Santtila, \& Sandnabba, 2010).

To date, the literature suggests that body dissatisfaction plays a prominent role in gender dysphoria, and in some cases body dissatisfaction appears to be a risk factor for the development of disordered eating. To the authors' knowledge, there has been no systematic review of the available literature pertaining to trans people, body dissatisfaction and disordered eating. Such a review will likely highlight important implications for clinicians working with trans people. In light of this, the aim is to critically and systematically review the available literature examining body dissatisfaction or disordered eating in a trans population, and also the literature pertaining to how body dissatisfaction and disordered eating are related in trans people.

\section{Method}

\section{Inclusion and exclusion criteria}

Articles selected were those that explored body dissatisfaction and/or disorder eating in trans people, as well as articles that explored how body dissatisfaction and disordered eating are related in trans individuals. Articles that may have not explored body dissatisfaction and/or disordered eating as a main outcome, but included a measure of body dissatisfaction and/or disordered eating, were included. Peer reviewed studies that were written in English, Spanish or Dutch languages were considered eligible. Studies were excluded if they were a case study or if they recruited participants who were intersex (i.e., people in which development of chromosomal, gonadal, or anatomical sex is atypical).

\section{Search strategy}

The PRISMA guidelines (Moher, Liberati, Tetzlaff, \& Altman, 2010) were followed to undertake this review. An electronic literature search was conducted using Web of Science, 
PubMed and PsychInfo search engines. The searches included papers published from 1966 to April 2015. To obtain potentially relevant papers the following search terms were used in relation to trans people: gender dysphoria, gender identity disorder, transgender, transsexual, LGBT. Within each search engine, these terms were combined with terms relating to disordered eating using the “AND” operator: Anorexia Nervosa, Bulimia Nervosa, disordered eating, Eating Disorders not Otherwise Specified, eating concerns, eating problems. Additionally, the trans terms were combined (using "AND”) with body image terms: body image, body uneasiness, body dissatisfaction, body satisfaction. The reference lists of relevant papers were also searched to identify any additional papers and corresponding authors were contacted for unpublished data.

\section{Article selection}

Seventy-four publications were identified from the literature search as being potentially relevant to the aims of this review (see Figure 1). Of these papers, 47 related to body image and trans people, 19 related to eating disorders and trans people, and eight related to body image, eating disorders and trans people. After screening the abstracts of these articles, 45 were excluded as they were a dissertation, conference paper, case study, or included participants who were intersex. Twenty-nine papers were then downloaded and, after full text review, 26 papers were included, all of which were peer reviewed and written in English (see Figure 1).

\section{Insert Figure 1 around here}

\section{Quality assessment}

To determine the methodological quality of the studies included in this review, the National Institute of Health and Clinical Excellence (NICE, 2007) checklists for cohort studies and qualitative studies were utilised (see Table 1). To complement the NICE (2007) checklist, Gilbert's (2009) checklist for assessing cross-sectional studies was also employed as there are no NICE guidelines for studies using this methodology (see Table 1). The NICE (2007) and Gilbert (2009) guidelines were consulted for each study in turn and each criterion was rated as: well covered, adequately covered, poorly covered, not addressed, not reported, or not applicable. Additionally, each study was rated using NICE (2007) guidelines from good quality $(++)$ (when most of the criteria have been satisfied), reasonable quality $\left(^{+}\right)$(when 
some of the criteria have been satisfied), or poor quality (-) (when few or no criteria have been satisfied) (see Supplementary Table A). Based on the NICE (2007) and Gilbert (2009) guidelines, most studies ( $\mathrm{n}=17)$ were rated poor quality (-). Most studies failed to recruit a representative sample as most samples were consecutive referrals to a gender clinic or recruited through a LGBT organisation. The majority of studies provided good coverage of the inclusion/exclusion criteria and sample characteristics which aided the interpretation of findings.

\section{Insert Tables 1 around here}

\section{Results}

What follows is a presentation of the findings from the studies included within this systematic review. Study characteristics will be explored and, following this, studies exploring firstly body dissatisfaction in a trans population, secondly disordered eating in a trans population, and lastly body dissatisfaction and disordered eating in a trans population will be discussed. At the start of each section, the measures employed to assess these constructs will be outlined. A summary of all the studies included within this review can be found in Table 2.

\section{Insert Table 2 here}

\section{Study characteristics}

The oldest paper was published in 1975 (Lindgren \& Pauly, 1975) and the newest papers were published in 2015 (Becker et al., 2015; Colizzi, Costa, \& Todarello, 2015; Witcomb et al., 2015). Out of the 26 papers which met the criteria for inclusion in this review, 18 explored the prevalence of body image in a trans population (Bandini et al., 2013; Becker et al., 2015; Bozkurt et al., 2006; Colizzi et al., 2015; De Vries et al., 2011, 2014; Fisher et al., 2013, 2014; Fleming, MacGowan, Robinson, Spitz, \& Salt, 1982; Kozee, Tylka, \& Bauerband, 2012; Kraemer, Delsignore, Schnyder, \& Hepp, 2007; Lai, Chiu, Gadow, Gau, \& Hwu, 2010; Lindgren \& Pauly, 1975; Marone, Lacoella, Cecchini \& Ravenna, 1998; Pauly \& Lindgren, 1976; Smith, Van Goozen, Kuiper, \& Cohen-Kettenis, 2005; Steensma, McGuire, Kreukels, Beekman, \& Cohen-Kettenis, 2013; Wolfradt \& Neumann, 2001). Three studies explored disordered eating in trans individuals (Ålgars et al., 2012; Khoosal, Langham, Palmer, Terry, \& Minajagi, 2009; Silverstein, Carpman, Perlick, \& Perdue, 1990). Five papers related to both disordered eating and body image and explored the prevalence of these constructs (Ålgars et al., 2010; Cella, Iannaccone, \& Cotrufo, 2013; Witcomb et al., 2015; 
Vocks, Stahn, Loenser, \& Legenbauer, 2009; Wiseman \& Moradi, 2010). It is important to note that the studies included within the review that examined eating psychopathology did not explore clinically significant eating disorders because diagnostic tools were not employed.

In relation to the methodology of these studies, the majority were cross-sectional. This type of research design is limiting because cause and effect cannot be determined. A longitudinal research design can be employed to determine cause and effect and five studies included in this review employed this type of design (De Vries et al., 2011, 2014; Khoosal et al., 2009; Smith et al., 2005; Steensma et al., 2013). Only one study employed an experimental research design (Marone et al., 1998). Of the 26 studies, only eight had a control group (Bandini et al., 2013; Becker et al., 2015; Bozkurt et al., 2006; Fleming et al., 1982; Pauly \& Lindgren, 1976; Vocks et al., 2009; Wolfradt \& Neumann, 2001; Witcomb et al., 2015). For four of these studies, their control group included participants from the general population (i.e., they did not have a diagnosis of Gender Dysphoria) (Becker et al., 2015; Fleming et al., 1982; Pauly \& Lindgren, 1976; Wolfradt \& Neumann, 2001). Three studies compared data from a trans population to a cisgender population and to an eating disorder control group (Bandini et al., 2013; Vocks et al., 2009; Witcomb et al., 2015) and one study compared to a homosexual and cisgender control group (Bozkurt et al., 2006). Fourteen studies obtained an official DSM or ICD diagnosis which was determined by a clinician or a self-report measure (Bandini et al., 2013; Becker et al., 2015; Bozkurt et al., 2006; Colizzi et al., 2015; De Vries et al., 2011, 2014 Fisher et al., 2013, 2014; Khoosal et al., 2009; Kraemer et al., 2007; Lai et al., 2010; Smith et al., 2005; Steensma et al., 2013; Witcomb et al., 2015). In relation to sample size of trans participants, 12 studies had 100 or more trans participants, seven studies had 50-100 trans participants, and nine studies had fewer than 50 trans participants.

\section{Body dissatisfaction in trans people}

Body dissatisfaction in trans people: Measures used

Ten different measures were used by studies considered in this review to assess body image. Some papers employed more than one measure to assess their outcomes.

- Body Image Scale (BIS) (Lindgren \& Pauly, 1975): This was the most frequently employed body image measure which was used in six of the studies within this review (De Vries et al., 2014, 2011; Lindgren \& Pauly, 1975; Pauly \& Lindgren, 1976; Smith et al., 2005; Steensma et al., 2013). The BIS was developed specifically for assessing 
body image in trans people. It lists 30 body parts and the individual has to rate on a five-point satisfaction scale each body part and whether they may want this feature to be altered through medical or surgical treatment. The higher the score, the more body dissatisfaction reported.

- Body Uneasiness Test (BUT) (Cuzzolaro \& Vetrone, 2006): This was employed by five studies in this review (Bandini et al., 2013; Cella et al., 2013; Colizzi et al., 2015; Fisher et al., 2013, 2014). The measure has two parts: part A which measures weight phobia, body image concerns, avoidance, compulsive self-monitoring, detachment and depersonalisation; and part B which assesses worries about specific body parts (e.g., "I would do anything to change some parts of my body"). A high score indicates a higher level of body uneasiness. The BUT was developed and evaluated with an eating disorder population.

- Body-Cathexis scale (Secord \& Jourard, 1953): This measure was employed by two studies reported on within this review (Bozkurt et al., 2006; Fleming et al., 1982) and was developed with a US college population. It assesses the strength and direction of feeling which the individual has about each part or function of their body and also includes 55 items that represent the various conceptual aspects of the self. Participants are asked to choose one of five responses (e.g., 1= Have strong feelings and wish change could somehow be made, 5= Consider myself fortunate). A high scores indicates that an individual is more anxious about their body.

- Body Checking Questionnaire (Reas, Whisenhunt, Netemeyer, \& Williamson, 2002): This tool was employed by Vocks et al. (2009). It has three subscales: checking related to overall appearance, checking of specific body parts, and idiosyncratic checking rituals. A higher score indicates more intense body dissatisfaction. It was developed with an eating disorder population and US college women.

- Body Image Measure (FBek) (Strau $\beta$ \& Richter-Appelt, 1996): This was employed by Kraemer et al. (2007) and is recommended for use with psychiatric and psychosomatic disorders and for assessing body image concepts under sexological considerations. It is a multidimensional body self-relation questionnaire and has three subscales; insecurity/concern (e.g., "My body does whatever it wants”), attractiveness/self-confidence (e.g., "I am satisfied with my body weight and body height”), and accentuation of body appearance (e.g., "My appearance is important to me”). A high score indicates more body image concerns. 
- Objectified Body Consciousness scale (OBC) (McKinley \& Hyde, 1996): This was employed by Wiseman and Moradi (2010) and has three subscales; body surveillance, body shame and appearance control beliefs. A high score on the OBC would indicate a more negative body experience. It was developed and validated with a non-clinical, female population.

- Drive for Muscularity Scale (McCreary \& Sasse, 2000): This measures attitudes and behaviour regarding one’s looks and muscularity (e.g., "I think that my arms are not muscular enough”) was employed by Vocks et al. (2009). Higher scores indicate a greater drive for muscularity.

- Body Image Questionnaire (BIQ) (Clement \& Löwe, 1996): This measure was employed by Wolfradt and Neumann (2001) and assesses 'the dynamic body image' (e.g., “I feel very fit”) and 'rejected body image’ (e.g., “My body often annoys me”). Higher scores are related to a more negative body image.

- Hamburg Body Drawing Scale (Appelt \& Strauss, 1988): This was employed by Becker et al. (2015) and Witcomb et al. (2015). This tool is a pictorial measure that assesses 33 different body parts in relation to body (dis)satisfaction and has recently been validated with a trans population (Becker et al., 2015). A higher score indicates higher levels of body dissatisfaction.

- Transgender Congruence Scale: This was developed and employed by Kozee et al. (2012) has two subscales; 'Gender Identity Acceptance’ and 'Appearance Congruence' (e.g., the degree to which a trans person perceives their external appearance to represented their gender identity). A higher score is related to body satisfaction. It was developed and empirically tested with a trans population.

Body dissatisfaction in trans people: Review of the studies

Eighteen studies identified in this review addressed gender dysphoria and body image without looking into disordered eating (see Table 2). The findings appear to suggest that lower transgender congruence between external presentation and internal self is related to lower levels of body satisfaction (Kozee et al., 2012). This low level of body satisfaction is not thought to be found within cisgender populations. As an example, Steensma et al. (2013) recruited trans individuals who met all or some of the criteria for Gender Dysphoria (DSMIV) during childhood and followed them up in adolescence. They found that those who reapplied to the gender clinic in adolescence $(n=47)$ reported more body dissatisfaction in 
comparison to those who did not reapply ( $\mathrm{n}=80$ ) (it was presumed that their gender dysphoria had desisted). These findings suggest that body image is related to gender dysphoria although it must be considered that not all participants met all the DSM-IV criteria.

Body dissatisfaction may be experienced in relation to specific body parts. Marone et al. (1998) were the first to explore body dissatisfaction in a trans population and found a gender difference in relation to eye gaze for specific body parts. Both trans males and females gazed at their feet for the shortest amount of time, indicating that they perceived less dissatisfaction regarding this body part. Trans females gazed longest at their whole body whereas trans males gazed longest at their chest, therefore suggesting that these body parts caused the most dissatisfaction. In comparison to trans males, trans females gazed at their genitals longer, suggesting they were more dissatisfied with these body parts than trans males. In support of these findings, trans females have been found to dislike more body parts than trans men (Fisher et al., 2013). Recently, Becker et al. (2015) also found trans males to perceive body dissatisfaction regarding all female body parts, not just sex-specific body parts. In contrast, trans females reported being extremely dissatisfied with sex-specific body parts (e.g., body hair, genitals). They concluded that whist sexual reassignment (i.e., hormones and/or Sex Reassignment Surgery; SRS) may increase body satisfaction for a trans person, enhancing body image should also take a more holistic stance, paying more attention to the psychological component of body image. In contrast to these findings, Bozkurt et al. (2006) found that although there was some difference in body satisfaction with some parts of the body, body satisfaction did not significantly differ in homosexual people $(n=36)$, trans females $(n=52)$, and aged matched heterosexual cisgender people $(n=72)$. They concluded that trans people experience similar levels of body dissatisfaction in comparison to homosexual and cisgender people.

The successfulness of gender dysphoria treatment in relieving body dissatisfaction suggests that body image plays a central role in gender dysphoria (Fleming et al., 1982; Kraemer et al., 2007; Lindgren \& Pauly, 1975; Pauly \& Lindgren, 1976; Smith et al., 2005; Wolfradt \& Neumann, 2001). Lindgren and Pauly (1975) and Pauly and Lindgren (1976), who were the first to explore the effectiveness of gender dysphoria treatment, found that after sexual reassignment treatment (i.e., hormones and/or SRS), body dissatisfaction levels reduced in both trans females and males. 
To determine at what stage of treatment trans individuals become more or less satisfied with their bodies, De Vries et al. (2011) assessed trans people $(n=70)$ at two different time points; once shortly after their first visit to the gender identity clinic (T0; mean age=13.65 years) and once shortly before starting CHT (T1; mean age=16.64 years). They found that between T0 and T1 (mean age=14.75 years), participants started puberty suppression (Gonadotrophinreleasing hormone agonists; GnRHa). GnRHa did not significantly reduce levels of body dissatisfaction between T0 and T1. Interestingly, between T0 and T1, natal females became more dissatisfied with their secondary and neutral sexual characteristics compared to males. The authors concluded that body dissatisfaction only suppresses once trans individuals undergo CHT. However, it must be noted that the participants in this study were adolescents, a demographic for whom body dissatisfaction is more prevalent in comparison to other age groups (e.g., Tiggemann, 2004) although body dissatisfaction exists in women of all ages (Runfola et al., 2013). De Vries et al. (2014) followed up this study with 55 trans individuals (from the original dataset) and with an additional time point, one year after SRS (T2). Body image concerns continued to remit after SRS for both primary and secondary sex characteristics. There was no significant difference for neutral body characteristics between T0 and T2. In combination, De Vries et al.'s $(2014,2011)$ studies suggest that body dissatisfaction only starts to remit after sexual reassignment, which appears to be in relation to sex-specific body parts. However, Fisher et al. (2014) suggested that it is not always necessary for trans people to undergo invasive treatment (i.e., SRS) to feel satisfied with their bodies. They found that when trans females received a cumulative dose of CHT, body uneasiness was relieved.

To put body dissatisfaction into context at different stages of treatment, Bandini et al. (2013) compared body image scores from 100 trans people with a DSM-IV GID diagnosis (50 without SRS and 50 with SRS), 88 eating disorder patients, and 107 controls. They found that in comparison to controls, trans individuals without SRS had higher levels of body uneasiness, similar to those with eating disorders. Additionally, trans individuals who had SRS reported body uneasiness levels that were not as low as controls, but they were lower than the trans people who had not had SRS and lower than the eating disorder participants' levels. This study's findings support the view that SRS relieves body uneasiness.

Gender dysphoria has been reported to co-occur with other disorders that affect body image. Lai et al. (2010) recruited 5010 first year University students, 225 of whom self-reported Gender Identity Disorder (GID), and found that body dysmorphic disorder (a condition 
included within DSM-5 that causes a person to have a distorted perception of their body and consequently feel anxious about their appearance) co-occurred with GID in trans males (40.8\%) and females (35.2\%). Levels of body dysmorphic disorder in participants that did not report GID were $15.2 \%$ and $20.2 \%$ in cisgender males and cisgender females, respectively. Colizzi et al. (2015) explored the comorbidity of dissociative disorder in trans patients. Dissociative disorder is a DSM-5 condition that alters a person's sense of reality. People with this condition may feel their body is unreal and they may have different identities, and therefore it is thought to be similar to gender dysphoria (Colizzi et al., 2015). Colizzi and colleagues found that trans patients with a dissociative disorder also reported higher levels of body uneasiness in comparison to trans patients who did not report a dissociative disorder. As a result of these findings the authors questioned whether body uneasiness is a genuine symptom of gender dysphoria or an expression of pathological dissociative experiences. Dissociation may also be a result of gender dysphoria, in the sense that trans people may be unable to connect with their bodies.

The body image and gender dysphoria findings, when taken together, appear to indicate that there is an association between body dissatisfaction and gender dysphoria. Body image concerns appear to be core to the distress that trans individuals experience prior to gender dysphoria treatment, given the evidence which suggests that treatment appears to alleviate at least some of the unhappiness trans individuals experience in relation to their bodies.

\section{Disordered eating in trans people}

\section{Disordered eating in trans people: Measures used}

Three different disordered eating measures were employed by studies considered in this review.

- Eating Disorder Inventory version 1, 2 and 3 (EDI-1-2-3) (Garner, Olmstead, \& Polivy, 1983; Garner, 1991; Garner, 2004): This was the most frequently used measure, which was used four times by studies considered within this review (Ålgars et al., 2012; Cella et al., 2013; Khoosal et al., 2009; Witcomb et al., 2015). This measure was developed for an eating disorder population and explores symptoms and psychological characteristics commonly related to eating disorders. The first three subscales (drive for thinness, bulimia and body dissatisfaction) relate to features of eating disorders. High scores indicate more disordered eating. 
- Eating Attitude Test (EAT-26) (Garner \& Olmsted, 1982): This tool was employed twice by studies considered in this review (Ålgars et al., 2010; Wiseman \& Moradi, 2010). It assesses the cognitive, attitudinal and behavioural dimensions of eating behaviour. It has three subscales: dieting; bulimia and food preoccupation; and, oral control. High scores indicate more disordered eating.

- Eating Disorder Examination Questionnaire (EDE-Q) (Fairburn \& Beglin, 1993): This was employed once by Vocks et al. (2009). It assesses eating behaviour and weight concerns (e.g., Over the past 4 weeks, have you wanted your stomach to be empty?) and has four subscales: restraint, eating, shape and weight concern. Higher scores indicate higher levels of eating disorder psychopathology.

\section{Disordered eating in Trans people: review of studies}

It has been suggested that individuals diagnosed with Gender Dysphoria are also at risk of disordered eating (e.g., Ålgars et al., 2010). Within this review, three studies explored the relationship between disordered eating and gender dysphoria (see Table 2). Silverstein et al. (1990) recruited 188 women at a University in the US. They found that women who reported a gender identity conflict were more likely to also report purging or frequent binging in comparison to the women in the study who did not report a conflicted gender identity. However, this study did not establish whether participants who reported a gender identity conflict had an ICD or DSM diagnosis of Gender Dysphoria. Ålgars et al. (2012) also set out to explore disordered eating by measuring eating behaviour and cognitions in a trans population. They found that the majority of trans individuals reported current or past disordered eating in an attempt to suppress features of their biological gender or to accentuate features of their gender identity, although the trans participants did not report clinical levels of disordered eating on the EDI-3. These findings suggest that the participants were dissatisfied with their bodies as they were not congruent with their gender identity and so were engaging in disordered eating behaviours, potentially as a way to address this. A limitation of this study was the small sample size $(n=20)$ and self-identification of being trans.

Khoosal et al. (2009) explored how features of eating disorder behaviour may change over the course of physical treatments in a sample of trans females $(n=40)$ with an official ICD-10 diagnosis. They found that six months after SRS, trans females reported lower levels of eating psychopathology and body image dissatisfaction in comparison to people with an eating disorder and to the general population. 


\section{Body Dissatisfaction and Disordered Eating in Trans people}

Body dissatisfaction and disordered eating in Trans people: review of the studies

So far, the literature appears to suggest that body dissatisfaction plays a key role in the development of disordered eating ( $\AA$ lgars et al., 2012; Khoosal et al., 2009; Silverstein et al., 1990). Within this review, five papers were identified which explored disordered eating as well as body image in trans people (see Table 2). Three of these studies found that the trans participants had higher levels of body dissatisfaction and disordered eating (e.g., bulimic behaviour) in comparison to cisgender populations (Ålgars et al., 2010; Vocks et al., 2009) and heterosexual and homosexual men and women (Cella et al., 2013). In contrast, Wiseman and Moradi (2010) explored body image and disordered eating in a sexual minority population and found eating problems and body image concerns were rarely experienced. However, only $2 \%$ of this sample identified themselves as trans and therefore these findings are unlikely to be representative of the trans population. Strengthening these findings, Witcomb et al. (2015) found levels of disordered eating and body dissatisfaction to be higher in trans $(n=200)$ than cisgender people ( $n=200)$, suggesting trans may exhibit higher levels of disordered eating than controls. However, eating disorder patients $(n=200)$ had significantly higher levels of disordered eating and body dissatisfaction in comparison to trans people.

The studies presented in this section appear to suggest that trans individuals do not have clinically significant eating disorders but may display disordered eating and body dissatisfaction, although empirical research into potential explanations as to why trans people may engage in disordered eating is sparse.

\section{Discussion}

The aim of this review was to critically and systematically review the available literature examining body dissatisfaction or disordered eating in a trans population, and also the literature pertaining to how body dissatisfaction and disordered eating are related in trans people. Overall this review found that body dissatisfaction is core to the distress of trans people which may put some people at risk for disordered eating.

Body dissatisfaction appears to be core to the distress trans people experience prior to gender dysphoria treatment. This is likely to be a result of the incongruence between biological assigned sex and gender identity (e.g., Ålgars et al., 2012). In addition, trans women may 
internalise the commonly emphasised message in western culture that thin is beautiful. Thinideal internalisation is defined by the extent to which a person engages in behaviours designed to produce an approximation of these ideals (Thompson \& Stice, 2001). Additionally, trans women have reported striving for thinness to appear more feminine (Ålgars et al., 2012), which may suggest that trans women are vulnerable to these cultural messages. In cisgender populations, thin-ideal internalisation is thought to directly foster body dissatisfaction as this ideal is virtually unattainable for most females (e.g., Fitzsimmons-Craft, 2011; Thompson \& Stice, 2001). Achieving this ideal may be even more unrealistic for trans females as some bodily features cannot be altered medically or physically (i.e., broad shoulders). The male equivalent to drive for thinness is the drive for muscularity (McCreary \& Sasse, 2000). In a cisgender population, appearance comparisons and internalisations are associated with muscularity-orientated body dissatisfaction and risky body change behaviour (Karazsia \& Crowther, 2010). This is evidenced by Goodwin, Haycraft and Meyer (2014) who found that peer and family messages to become more muscular predicted compulsive exercise in teenage boys. In light of the review's findings and previous literature, clinicians working with trans people must be mindful that body dissatisfaction may be driven by gender dysphoria and also by culturally emphasised genderspecific ideals (which are probably unattainable) in order to achieve a more feminine or masculine body shape, depending on their gender identity.

This review also found that gender dysphoria treatment is capable of increasing body satisfaction (e.g., De Vries et al., 2014). This increase in body satisfaction is thought to be a result of sex-specific body parts becoming more congruent with gender identity (e.g., De Vries et al., 2014). However, interestingly, Becker et al. (2015) found trans males were dissatisfied with all female body parts (not just sex-specific) and therefore concluded that body image concerns in trans people should not be reduced to sex-specific body parts. This finding can be explained by the fact that not all body parts associated with natal females (e.g., curvaceous hips) and natal males (e.g., large hands) can be modified through body changing behaviours (i.e., surgery or exercise). In light of the review's findings and previous literature, it seems appropriate for clinicians to continue to monitor body dissatisfaction and utilise gender dysphoria treatments. At the same time, clinicians working with trans people should take a more holistic stance on body image. Rather than only focusing on improving satisfaction with sex-specific body parts through medical intervention, the psychological and social aspects of body image should be addressed (i.e., challenging negative thought 
processes about the body, positive re-framing of aspects that cannot be changed and challenging perceived negative reactions from society). For example, Cognitive Behavioural Therapy programmes targeted at US college women have been found to increase affective body image and decrease maladaptive body image cognitions (Butters \& Cash, 1987). At the same time, future research would benefit from taking a more holistic approach when measuring body image, instead of focusing on satisfaction with sex-specific body parts.

This review found that trans people engage in disordered eating (e.g., Khoosal et al., 2009). Only one study by Ålgars et al. (2012) explored why trans people may engage in this behaviour and found that trans people are motivated to engage in disordered eating to suppress features of their natal gender and accentuate features of their gender identity; thus they are motivated by their body dissatisfaction. This is a finding that has been replicated within cisgender populations; Stice and Shaw (2002) suggested that body dissatisfaction is the main contributor towards the onset and maintenance of an eating disorder. Within cisgender populations there are thought to be several moderating factors that influence the relationship between body dissatisfaction and eating disorders. McLean, Paxton and Wetheim (2010), for example, found that women were more likely to suffer from an eating disorder if they had a higher body mass index, if they placed high importance on their appearance, and if they had lower cognitive reappraisal and self-care scores. More recently, Machado et al. (2014) found perfectionism and a family history of an eating disorder to be prevalent in individuals who develop Anorexia Nervosa. Fortunately, the evidence from this current review suggests that disordered eating in trans people does not appear to be clinically significant (e.g., Witcomb et al., 2015). Perhaps in a trans population, body dissatisfaction does not manifest into an eating disorder since trans people are dissatisfied with aspects of their body (i.e., hands) that cannot be modified through diet restriction (Witcomb et al., 2015). It may also be that as body dissatisfaction improves with CHT and SRS (e.g., De Vries et al., 2014), disordered eating decreases, given that body dissatisfaction is thought to manifest disordered eating (Ålgars et al., 2012). In relation to clinical implications, clinicians working with trans people should be aware that disordered eating may be present. If this is the case, clinicians should work with the trans person to ascertain why the individual may be engaging in this disordered behaviour. This will help inform clinical choices regarding how best to address this disordered behaviour. Clinicians working in other areas should also be mindful that patients, both those identifying as trans and those yet to explore their gender identity, may present with disordered eating as a consequence of their gender dysphoria. In addition to 
this, more empirical research needs to explore why trans people may be at risk for disordered eating as there is currently only one study by Ålgars et al. (2012) that has explored potential explanations. Researchers should also explore bodily (dis)satisfaction with regard to body parts that cannot be modified through medical intervention (i.e., hands or feet). This in turn would enable a better understanding of body image in trans people which would inform clinical practice.

Despite these important findings, the review was limited by the methodological quality of studies considered within it. With regard to body dissatisfaction, numerous different measures were used to assess this construct. Even though interesting and varied findings have been produced from such studies, the lack of consistency means it is hard to make cross-study comparisons. The content of the measures employed to explore body image, disordered eating and gender dysphoria was also varied and sometimes limited. For instance, BIS (the most commonly employed body image measure) only taps into the cognitive dimension of body image and fails to recognise the attitudinal, perceptual, or behavioural dimensions. Therefore, this measure is unlikely to provide a comprehensive understanding of body image. The field would benefit from consolidating the most useful components of existing measures to develop a comprehensive and validated measure that taps all dimensions of body image. While cross-sectional research has identified an association between gender dysphoria, body image (e.g., Kozee, Tylka, \& Bauerband, 2012) and disordered eating (e.g., Ålgars et al., 2010), there is a lack of longitudinal research within the field. This is problematic as how body dissatisfaction and disordered eating change over time (i.e., during the treatment programme) is poorly understood. Studies also typically employed a small sample of trans people who did not always have a clinical diagnosis of Gender Dysphoria in accordance with the ICD or DSM. This prevents the generalisability of such findings to those who have an official diagnosis. In addition to the research areas' methodological limitations, the current systematic review also has some limitations which should be considered. This review only considered papers as being eligible for inclusion if they were written in English, Spanish or Dutch and therefore papers that may have been relevant but were written in other languages were not reviewed. This review also excluded studies that explored body image and/or disordered eating in intersex people and therefore the findings of this review cannot be generalised to this population. 
Body dissatisfaction and disordered eating in trans people 18

\section{Conclusion}

This systematic review has highlighted how body dissatisfaction is core to the distress of trans people which may put some people at risk for disordered eating. To enhance our understanding of body image and disordered eating in trans people, more methodologically robust research needs to be conducted (e.g., larger sample sizes, longitudinal designs). As a consequence, it is hoped that a more advanced empirical knowledgebase will be established, which in turn will inform clinical practice.

Declaration of interest: The authors report no conflict of interest. The authors alone are responsible for the content and writing of the paper. 


\section{References}

Ålgars, M., Alanko, K., Santtila, P., \& Sandnabba, N. K. (2012). Disordered Eating and Gender Identity Disorder: A Qualitative Study. Eating Disorders, 20, 300-311.

Ålgars, M., Santtila, P., \& Sandnabba, N. K. (2010). Conflicted gender identity, body dissatisfaction, and disordered eating in adult men and women. Sex Roles, 63, 118-125.

American Psyhcological Association. (2013). Diagnostic and statistical manual of mental disorders, (DSM-5). Washington DC: American Psychiatric Association.

Appelt, H., \& Strauss, B. (1988). Psychoendokrinologische Gyna "kologie: Ergebnisse und Perspektiven. [Psycho- endocrinological Gynaecology: results and prospects]. Stuttgart:Enke.

Arcelus, J., Bouman, W.P., Witcomb, G.L., Van De Noortgate, W., Claes, L., \& FernandezAranda, F. (2015). Prevalence of Transsexualism: A systematic review and meta-analysis. European Psychiatry Review, 30(6), 807-815.

Bandini, E., Fisher, A. D., Castellini, G., Lo Sauro, C., Lelli, L., Meriggiola, M. C., ... Ricca, V. (2013). Gender Identity Disorder and Eating Disorders: Similarities and Differences in Terms of Body Uneasiness. Journal of Sexual Medicine, 10, 1012-1023.

Becker, I., Nieder, T. O., Cerwenka, S., Briken, P., Kreukels, B. P. C., Cohen-Kettenis, P. T., ... Richter-Appelt, H. (2015). Body Image in Young Gender Dysphoric Adults: A European Multi-Center Study. Archives of Sexual Behavior.

Bozkurt, A., Isikli, H., Demir, F., Ozmenler, K. N., Gulcat, Z., Karlidere, T., \& Aydin, H. (2006). Body Image and Personality Traits of Male-To-Female Transsexuals and Homosexuals. Social Behavior and Personality: An International Journal, 34(8), 927-938.

Butters, J., \& Cash, T. (1987). Cognitive-behavioral treatment of women's body-image dissatisfaction. Journal of Consulting and Clinical Psychology, 55(6), 889-897.

Cella, S., Iannaccone, M., \& Cotrufo, P. (2013). Influence of gender role orientation (masculinity versus femininity) on body satisfaction and eating attitudes in homosexuals, heterosexuals and transsexuals. Eating and Weight Disorders - Studies on Anorexia, Bulimia and Obesity, 18, 115-124.

Clement, U., \& Lo“we, B. (1996). Die Validierung des FKB-20 als Instrument zur Erfassung von Ko"rperbildsto"rungen bei psychosomatischen Patienten. [The validation of the FKB20 as a tool for detection of body image disorders in psychosomatic patients] Psychosomatic Medicine and Psychotherapy, 46, 254-259.

Colizzi, M., Costa, R., \& Todarello, O. (2015). Dissociative symptoms in individuals with gender dysphoria: Is the elevated prevalence real? Psychiatry Research, 226(1), 173-80.

Cuzzolaro, M., Marano, G., Garfinkel, E. P., \& Vetrone, G. (2006). The Body Uneasiness Test (BUT): Development and validation of a new body image assessment scale. Eating and Weight Disorder, 11, 1-13. 
De Vries, A. L. C., Mcguire, J. K., Steensma, T. D., Eva, C. F., Doreleijers, T. A. H., \& Cohen-Kettenis, P. T. (2014). Young adult psychological outcome after puberty suppression and gender reassignment. Paediatrics, 134, 1-9.

De Vries, A. L. C., Steensma, T. D., Doreleijers, T. a H., \& Cohen-Kettenis, P. T. (2011). Puberty suppression in adolescents with gender identity disorder: A prospective follow-up study. Journal of Sexual Medicine, 8, 2276-2283.

Fairburn, C. G. (2008). Cognitive behavior therapy and eating disorders (p. 324). New York: Guilford Press.

Fairburn, C. G., \& Cooper, G. T. (1993). The eating disorder examination. In C. F. Fairburn \& G. T. Wilson (Eds.), Binge eating: Nature, assessment and treatment (pp. 317-332). New York: Guilford.

Fisher, A. D., Bandini, E., Casale, H., Ferruccio, N., Meriggiola, M. C., Gualerzi, A., ... Maggi, M. (2013). Sociodemographic and clinical features of gender identity disorder: An italian multicentric evaluation. Journal of Sexual Medicine, 10, 408-419.

Fisher, A. D., Castellini, G., Bandini, E., Casale, H., Fanni, E., Benni, L., ... Rellini, A. H. (2014). Cross-Sex Hormonal Treatment and Body Uneasiness in Individuals with Gender Dysphoria. Journal of Sexual Medicine, 11, 709-719.

Fitzsimmons-Craft, E. (2011). Social psychological theories of disordered eating in college women: Review and integration. Clinical Psychology Review, 13, 1224-1237.

Fleming, M. Z., MacGowan, B. R., Robinson, L., Spitz, J., \& Salt, P. (1982). The body image of the postoperative female-to-male transsexual. Journal of Consulting and Clinical Psychology, 50(3), 461-462.

Garner, D.M. (1991). Eating disorder inventory 2: Professional manual. Odessa, FL: Psychological Assessment Resources.

Garner, D. M. (2004). EDI 3: Eating Disorder Inventory-3: Professional Manual. Odessa, FL: Psychological Assessment Resources.

Garner, D. M., \& Olmsted, M. (1982). The eating attitudes test: Psychometric features and clinical correlates. Psychological Medicine, 12, 871-878.

Garner, D. M., Olmstead, M. P., \& Polivy, J. (1983). Development and validation of a multidimensional eating disorder inventory for anorexia nervosa and bulimia. International Journal of Eating Disorders, 2, 15-34.

Gilbert, N. (2009). Disclosure of eating disorders and subsequent help seeking. Doctoral dissertation, University of Birmingham. Retrieved from http://etheses.bham.ac.uk/428/

Goodwin, H., Haycraft, E., \& Meyer, C. (2014). Sociocultural Risk Factors for Compulsive Exercise: A Prospective Study of Adolescents. European Eating Disorders, 22(5), 360365. 
Karazsia, B., \& Crowther, J. (2010). Sociocultural and psychological links to men's engagement in risky body change behaviors. Sex Roles, 63(9-10), 747-756.

Khoosal, D., Langham, C., Palmer, B., Terry, T., \& Minajagi, M. (2009). Features of eating disorder among male-to-female transsexuals. Sexual and Relationship Therapy, 24, 217229.

Kozee, H. B., Tylka, T. L., \& Bauerband, L. A. (2012). Measuring Transgender Individuals' Comfort With Gender Identity and Appearance: Development and Validation of the Transgender Congruence Scale. Psychology of Women Quarterly, 36(2), 179-196.

Kraemer, B., Delsignore, A., Schnyder, U., \& Hepp, U. (2007). Body image and transsexualism. Psychopathology, 41, 96-100.

Kroon Van Diest, A. M., \& Perez, M. (2013). Exploring the integration of thin-ideal internalization and self-objectification in the prevention of eating disorders. Body Image, 10(1), 16-25.

Lai, M. C., Chiu, Y. N., Gadow, K. D., Gau, S. S. F., \& Hwu, H. G. (2010). Correlates of gender dysphoria in Taiwanese University students. Archives of Sexual Behavior, 39, 1415-1428.

Lindgren, T., \& Pauly, I. (1975). A body image scale for evaluating transsexuals. Archives of Sexual Behavior, 4, 639-656

Machado, B. C., Gonçalves, S. F., Martins, C., Hoek, H. W. and Machado, P. P. (2014), Risk Factors and Antecedent Life Events in the Development of Anorexia Nervosa: A Portuguese Case-Control Study. European Eating Disorders Review, 22: 243-251.

Marone, P., Lacoella, S., Cecchini, M. G., \& Ravenna, A. R. (1998). An experimental study of body image and perception in gender identity disorders. International Journal of Transgenderism, 2(3). Retrieved from http://www.iiav.nl/ezines/web/ijt/9703/numbers/symposion/ijtc0501.htm

McCreary, D., \& Sasse, D. (2000). An exploration of the drive for muscularity in adolescent boys and girls. Journal of American College Health, 48(6), 297-304.

McKinley, N. M., \& Hyde, J. S. (1996). The Objectified Body Consciousness Scale Development and Validation. Psychology of Women Quarterly, 20, 181-215.

McLean, S.A., Paxton, J. S. \& Wetheim., E. W. (2010). Factors associated with body dissatisfaction and disordered eating in women in midlife. International Journal of Eating Disorders, 43(6), 527-536.

Moher, D., Liberati, A., Tetzlaff, J., \& Altman, D. G. (2010). Preferred reporting items for systematic reviews and meta-analyses: the PRISMA statement. International Journal of Surgery (London, England), 8(5), 336-41. 
NICE. (2007). The guidelines manual. London: National Institute for Health and Care Excellence. Retrieved from https://www.nice.org.uk/article/pmg6/chapter/6-reviewingtheevidence

Pauly, I. B., \& Lindgren, T. W. (1976). Body Image and Gender Identity. Journal of Homosexuality, 2(2), 133-142.

Reas, D. L., Whisenhunt, B. L., Netemeyer, R., \& Williamson, D. a. (2002). Development of the body checking questionnaire: A self-report measure of body checking behaviors. International Journal of Eating Disorders, 31, 324-333.

Runfola, C. D., Von Holle, A., Trace, S. E., Brownley, K. A., Hofmeier, S. M., Gagne, D. A. and Bulik, C. M. (2013), Body Dissatisfaction in Women Across the Lifespan: Results of the UNC-SELF and Gender and Body Image (GABI) Studies. Europena Eating Disorders Review, 21: 52-59.

Secord, P. F., \& Jourard, S. M. (1953). The appraisal of body-cathexis: body-cathexis and the self. Journal of Consulting Psychology, 17(7), 343-347.

Silverstein, B., Carpman, S., Perlick, D., \& Perdue, L. (1990). Nontraditional sex role aspirations, gender identity conflict, and disordered eating among college women. Sex Roles, 23(11-12), 687-695.

Smith, Y. L. S., Van Goozen, S. H. M., Kuiper, A. J., \& Cohen-Kettenis, P. T. (2005). Sex reassignment: outcomes and predictors of treatment for adolescent and adult transsexuals. Psychological Medicine, 35, 89-99.

Steensma, T. D., McGuire, J. K., Kreukels, B. P. C., Beekman, A. J., \& Cohen-Kettenis, P. T. (2013). Factors associated with desistence and persistence of childhood gender dysphoria: A quantitative follow-up study. Journal of the American Academy of Child and Adolescent Psychiatry, 52(6), 582-590.

Stice, E., \& Shaw, H. E. (2002). Role of body dissatisfaction in the onset and maintenance of eating pathology. Journal of Psychosomatic Research, 53(5), 985-993.

Strauß, B., \& Richter-Appelt, H. (1996). Fragebogen zur Beurteilung des eigenen Ko“rpers (FBeK) [Questionnaire for the assessment of one’s body]. Gu^ ${ }^{\sim}$ ttingen: Hogrefe.

Thompson, J., \& Stice, E. (2001). Thin-ideal internalization: Mounting evidence for a new risk factor for body-image disturbance and eating pathology. Current Directions in Psychological Science, 10(5), 181-183.

Tiggemann, M. (2004). Body image across the adult life span: Stability and change. Body Image, 1, 29-41.

Vocks, S., Stahn, C., Loenser, K., \& Legenbauer, T. (2009). Eating and body image disturbances in male-to-female and female-to-male transsexuals. Archives of Sexual Behavior, 38, 364-377. 
Wiseman, M. C., \& Moradi, B. (2010). Body image and eating disorder symptoms in sexual minority men: A test and extension of objectification theory. Journal of Counseling Psychology, 57(2), 154-166.

Witcomb, G. L., Arcelus, J., \& Chen, J. (2013). Can cognitive dissonance methods developed in the West for combatting the "thin ideal" help slow the rapidly increasing prevalence of eating disorders in non-Western cultures? Shanghai Archives of Psychiatry, 25(6), 332-40.

Witcomb, G. L., Bouman, W. P., Brewin, N., Richards, C., Fernandez-Aranda, F., \& Arcelus, J. (2015). Body Image Dissatisfaction and Eating-Related Psychopathology in Trans Individuals: A Matched Control Study. European Eating Disorders Review, 23, 287-293.

Wolfradt, U., \& Neumann, K. (2001). Depersonalization, self-esteem and body image in male-to-female transsexuals compared to male and female controls. Archives of Sexual Behavior, 30(3), 301-310.

World Health Organization. (1992). The ICD-10 classification of mental and behavioural disorders: Clinical descriptions and diagnostic guidelines. Geneva: World Health Organization. 
Table 1: Gilbert (2009) and NICE (2007) methodological criteria used for rating the quality of the studies considered in the systematic review

\begin{tabular}{|c|c|}
\hline Gilbert (2009) & Criteria \\
\hline $\begin{array}{l}\text { Section 1: Internal } \\
\text { Validity }\end{array}$ & 1.1 The study assessed an appropriate and clearly focused question \\
\hline $\begin{array}{l}\text { Selection of } \\
\text { Subjects }\end{array}$ & $\begin{array}{l}\text { 1.3 Representative cases from relevant population } \\
\text { 1.4 The study indicates how many of the people asked to take part did so } \\
\text { 1.5 Comparison is made between participants and non-participants } \\
\text { 1.6 Inclusion criteria are made explicit and sample characteristics sufficiently } \\
\text { described } \\
\text { 1.7 Were subjects recruited over the same period of time? }\end{array}$ \\
\hline Data Collection & $\begin{array}{l}\text { 1.8 Confidence in the quality of individual responses } \\
\text { 1.9 Outcome is measured in an objective, standard, valid and reliable way } \\
\text { 1.10 Reliance on real information rather than recall/hypothetical scenarios }\end{array}$ \\
\hline Confounding & $\begin{array}{l}\text { 1.11 The main potential confounders are identified and taken into account in } \\
\text { the design and analysis } \\
\text { 1.12 Minimisation of bias - (e.g., participant bias observer bias, halo effect) }\end{array}$ \\
\hline Statistical Analysis & $\begin{array}{l}\text { 1.13 Appropriate use of statistical analysis } \\
\text { 1.14 Actual P value reported }\end{array}$ \\
\hline $\begin{array}{l}\text { Section 2: Overall } \\
\text { assessment of the } \\
\text { study }\end{array}$ & $\begin{array}{l}2.1 \text { Taking into account clinical considerations, your evaluation of the } \\
\text { methodology used and the statistical power of the study, are you certain the } \\
\text { findings could be replicated? }\end{array}$ \\
\hline \multirow[t]{3}{*}{$\begin{array}{l}\text { NICE (2007) rating } \\
\text { criteria }\end{array}$} & $\begin{array}{l}++\quad \text { The majority of criteria have been satisfied and where they have not, } \\
\text { the conclusions from the study are unlikely to change. }\end{array}$ \\
\hline & $\begin{array}{l}+\quad \text { Some of the criteria have been satisfied and those criteria that are not } \\
\text { satisfied are not thought to alter the conclusions of the study. }\end{array}$ \\
\hline & $\begin{array}{l}\text { - Very few or none of the criteria are satisfied. The conclusions of the } \\
\text { study are thought to alter. }\end{array}$ \\
\hline
\end{tabular}


Table 2: Body dissatisfaction and/or disordered eating in trans people

\begin{tabular}{|c|c|c|c|c|c|c|c|}
\hline Author(s) & Year & $\begin{array}{l}\text { Country that the } \\
\text { study was } \\
\text { conducted in }\end{array}$ & Participants & Outcome measures (relevant) & $\begin{array}{l}\text { Classification } \\
\text { System } \\
\text { (Transsexualis } \\
\text { m/Gender } \\
\text { Dysphoria) }\end{array}$ & Stage of Transition & Main finding(s) \\
\hline Algars et al. & 2012 & Finland & $\begin{array}{l}\mathrm{N}=20 \text { ( } \mathrm{n}=11 \text { trans males, } \\
\mathrm{n}=9 \text { trans females) }\end{array}$ & EDI & None & $\begin{array}{l}\text { Four participants had no } \\
\text { medical intervention, } 16 \text { had } \\
\text { undergone CHT (12/16 had } \\
\text { undergone SRS). }\end{array}$ & $\begin{array}{l}\text { No trans people report clinically } \\
\text { significant eating disorders }\end{array}$ \\
\hline $\begin{array}{l}\text { Algars, Santtila } \\
\text { \& Sandnabba }\end{array}$ & 2010 & Finland & $\begin{array}{l}\mathrm{N}=1,142 \text { (Gender Conflict } \\
\mathrm{n}=571 \text {, cisgender } \mathrm{n}=571)\end{array}$ & EAT & None & Information not collected & $\begin{array}{l}\text { Trans females > disordered eating } \\
\text { than controls }\end{array}$ \\
\hline Bandini et al. & 2013 & Italy & $\begin{array}{l}\mathrm{N}=295 \text { (Gender Dysphoria } \\
\mathrm{n}=100 \text {, Eating Disorder } \\
\mathrm{n}=88 \text {, Controls } \mathrm{n}=107 \text { ) }\end{array}$ & BUT & DSM & $\begin{array}{l}\text { Pre- SRS. Eating disorder } \\
\text { participants were at the } \\
\text { assessment stage }\end{array}$ & $\begin{array}{l}\text { Trans individuals without SRS } \\
\text { had }>\text { body uneasiness, similar to } \\
\text { those with eating disorders }\end{array}$ \\
\hline Becker et al. & 2015 & Germany & $\begin{array}{l}\mathrm{N}=250(\mathrm{n}=135 \text { trans males, } \\
\mathrm{n}=115 \text { trans females })\end{array}$ & Hamburg Body Drawing Scale & DSM & Assessment stage & $\begin{array}{l}\text { Trans males reported body } \\
\text { dissatisfaction regarding all female } \\
\text { body parts } \\
\text { Trans females= dissatisfied with } \\
\text { sex-specific body parts }\end{array}$ \\
\hline Bozkurt et al. & 2006 & Turkey & $\begin{array}{l}\mathrm{N}=160(\mathrm{n}=52 \text { trans } \\
\text { females, } \mathrm{n}=36 \\
\text { homosexuals, } \mathrm{n}=72 \\
\text { controls) }\end{array}$ & BCS & DSM & Not reported & $\begin{array}{l}\text { Trans people are not more } \\
\text { dissatisfied with their bodies in } \\
\text { comparison to homosexuals and } \\
\text { controls }\end{array}$ \\
\hline $\begin{array}{l}\text { Cella, } \\
\text { Iannaccone \& } \\
\text { Cotufo }\end{array}$ & 2013 & Italy & $\begin{array}{l}\mathrm{N}=325(\mathrm{n}=132 \\
\text { homosexuals, } \mathrm{n}=178 \\
\text { heterosexuals, } \mathrm{n}=15 \\
\text { Gender Dysphoria) }\end{array}$ & $\begin{array}{l}\text { EDI-2 } \\
\text { BUT }\end{array}$ & None & Assessment stage & $\begin{array}{l}\text { Trans participants > body } \\
\text { dissatisfaction and eating disorder } \\
\text { behaviour and attitudes in } \\
\text { comparison to homosexuals and } \\
\text { heterosexuals }\end{array}$ \\
\hline $\begin{array}{l}\text { Colizzi Coasta \& } \\
\text { Todarello }\end{array}$ & 2015 & Italy & $\begin{array}{l}\mathrm{N}=118(\mathrm{n}=82 \text { trans } \\
\text { females, } \mathrm{n}=36 \text { trans males) }\end{array}$ & BUT & DSM & All CHT (n=22 SRS) & $\begin{array}{l}\text { Trans patients with a dissociative } \\
\text { disorder > body uneasiness in } \\
\text { comparison to trans patients who } \\
\text { did not report a dissociative } \\
\text { disorder }\end{array}$ \\
\hline De Vries et al. & 2014 & Netherlands & $\begin{array}{l}\mathrm{N}=55(\mathrm{n}=22 \text { transwomen, } \\
\mathrm{n}=33 \text { transmen) }\end{array}$ & BIS & DSM & $\begin{array}{l}\text { Participants were assessed at } \\
\text { intake pre-treatment (T0), } \\
\text { during treatment (T1, initiation } \\
\text { of CHT) and post-treatment } \\
\text { (T2, one year after SRS) }\end{array}$ & $\begin{array}{l}\text { Body image concerns continued to } \\
\text { remit after SRS }\end{array}$ \\
\hline De Vries et al. & 2011 & Netherlands & $\begin{array}{l}\mathrm{N}=70 \text { ( } \mathrm{n}=33 \text { natal males, } \\
\mathrm{n}=37 \text { natal females) }\end{array}$ & BIS & DSM & $\begin{array}{l}\text { Participants were assessed } \\
\text { twice: once shortly after their } \\
\text { first visit (T0) and shortly } \\
\text { before starting CHT (T1). } \\
\text { During T0 and T1 participants }\end{array}$ & $\begin{array}{l}\text { GnRHa does not significantly } \\
\text { reduce levels of body dissatisfaction } \\
\text { between T0 and T1 }\end{array}$ \\
\hline
\end{tabular}


Body dissatisfaction and disordered eating in trans people 26

\begin{tabular}{|c|c|c|c|c|c|c|c|}
\hline & & & & & & $\begin{array}{l}\text { started on puberty suppression } \\
\text { (GnRHa) }\end{array}$ & \\
\hline Fisher et al. & 2013 & Italy & $\begin{array}{l}N=140(n=92 \text { trans } \\
\text { females, } n=48 \text { trans males) }\end{array}$ & BUT & DSM, ICD & All had not undergone SRS & $\begin{array}{l}\text { There was a prevalence of } 0.7 \% \text { of } \\
\text { eating disorders. Trans females } \\
\text { dislike more body parts then trans } \\
\text { men }\end{array}$ \\
\hline Fisher et al. & 2014 & Italy & $\begin{array}{l}N=125(n=66 \text { trans } \\
\text { females, } n=59 \text { trans males })\end{array}$ & BUT & DSM & $\begin{array}{l}\text { Trans females }=24 \text { had never } \\
\text { take CHT, } 42 \text { were taking } \\
\text { CHT. Trans males }=33 \text { had } \\
\text { never taken CHT and } 26 \text { were } \\
\text { on CHT. All pre-SRS. }\end{array}$ & $\begin{array}{l}\text { CHT can alleviate body uneasiness } \\
\text { without surgery in trans females }\end{array}$ \\
\hline Fleming et al. & 1982 & USA & $\begin{array}{l}\mathrm{N}=44(\mathrm{n}=22 \text { postsurgical } \\
\text { trans males, } \mathrm{n}=22 \text { controls })\end{array}$ & BCS & None & $\begin{array}{l}\text { Nine had not had hysterectomy, } \\
8 \text { had hysterectomy but not } \\
\text { phalloplasty, and } 5 \text { had } \\
\text { phalloplasty }\end{array}$ & SRS $>$ bodily satisfaction \\
\hline Khoosal et al & 2009 & England & $\begin{array}{l}\mathrm{N}=40 \text { (compared to } \\
\text { Garners normative data) }\end{array}$ & EDI & ICD & $\begin{array}{l}\text { Had undergone sexual } \\
\text { reassignment surgery }\end{array}$ & SRS> body satisfaction \\
\hline Kraemer et al. & 2007 & Switzerland & $\begin{array}{l}\mathrm{N}=45 \text { ( } \mathrm{n}=23 \text { pre-operative, } \\
\mathrm{n}=22 \text { post-operative) }\end{array}$ & Body Image Measure (FBeK) & DSM & 23 pre-SRS, 22 post-SRS & SRS > body satisfaction \\
\hline $\begin{array}{l}\text { Kozee, Tylka \& } \\
\text { Bauerband }\end{array}$ & 2012 & USA & Study 2: N=342 & Transgender Congruence Scale & None & Information not collected & $\begin{array}{l}\text { Transgender congruence < body } \\
\text { dissatisfaction }\end{array}$ \\
\hline Lai et al. & 2010 & China & $\begin{array}{l}N=5010 \text { (gender dysphoria } \\
n=225 \text {, cisgender } n=4785 \text { ) }\end{array}$ & Adult self-report Inventory-4 & DSM & Information not reported & $\begin{array}{l}\text { Body dysmorphic disorder was } \\
\text { associated with gender dysphoria in } \\
\text { female (35.2\%) and males ( } 40.8 \%)\end{array}$ \\
\hline $\begin{array}{l}\text { Lindgren \& } \\
\text { Pauly }\end{array}$ & 1975 & USA & $\begin{array}{l}\mathrm{N}=32(\mathrm{n}=16 \text { trans males, } \\
\mathrm{n}=16 \text { trans female) }\end{array}$ & BIS & None & $\begin{array}{l}\text { Some participants were tested } \\
\text { during the assessment period } \\
\text { and others after the start of } \\
\text { hormone treatment (exact } \\
\text { numbers are not given). One } \\
\text { participant had undergone SRS }\end{array}$ & $\begin{array}{l}\text { Sexual reassignment > body } \\
\text { satisfaction }\end{array}$ \\
\hline Marone et al. & 1998 & Italy & $\begin{array}{l}\mathrm{N}=30 \text { ( } \mathrm{n}=15 \text { trans females, } \\
\mathrm{n}=15 \text { trans males })\end{array}$ & $\begin{array}{l}\text { Sensory Integration Body } \\
\text { Imagery Test }\end{array}$ & None & None had SRS & $\begin{array}{l}\text { Trans females are most dissatisfied } \\
\text { with their whole body } \\
\text { Trans males are most dissatisfied } \\
\text { with their chest }\end{array}$ \\
\hline $\begin{array}{l}\text { Pauly \& } \\
\text { Lindgren }\end{array}$ & 1976 & USA & $\begin{array}{l}\mathrm{N}=131(\mathrm{n}=66 \text { gender } \\
\text { dysphoria, } \mathrm{n}=65 \text { controls })\end{array}$ & BIS & None & $\begin{array}{l}30 \text { assessment, } 27 \text { post-CHT, } 9 \\
\text { SRS }\end{array}$ & SRS > body image satisfaction \\
\hline $\begin{array}{l}\text { Silverstein \& } \\
\text { Carpman }\end{array}$ & 1990 & USA & $\mathrm{N}=188$ & $\begin{array}{l}\text { Disordered eating was } \\
\text { measured by questions found } \\
\text { by Silverstein et al. (1988) } \\
\text { Draw-A-Person test }\end{array}$ & None & Not reported & $\begin{array}{l}\text { Participants who reported a } \\
\text { conflicted gender identity were also } \\
\text { more likely to report eating disorder } \\
\text { behaviours }\end{array}$ \\
\hline Smith et al. & 2005 & Netherlands & $\begin{array}{l}\mathrm{N}=162(\mathrm{n}=104 \text { trans } \\
\text { females, } \mathrm{n}=58 \text { trans males })\end{array}$ & $\begin{array}{l}\text { BIS } \\
\text { Appraisal of Appearance } \\
\text { Inventory }\end{array}$ & DSM & $\begin{array}{l}52 \text { participants: breast } \\
\text { augmentation. } \\
10 \text { participants: } \\
\text { phalloplasty } \\
\end{array}$ & SRS > body image satisfaction \\
\hline
\end{tabular}


Body dissatisfaction and disordered eating in trans people 27

\begin{tabular}{|c|c|c|c|c|c|c|c|}
\hline Steensma et al. & 2013 & Netherlands & $\begin{array}{l}\mathrm{N}=127(\mathrm{n}=79 \text { boys and } \\
\mathrm{n}=48 \text { girls })\end{array}$ & BIS & DSM & $\begin{array}{l}47 \text { of the participants reapplied } \\
\text { to the gender clinic in } \\
\text { adolescents, requested medical } \\
\text { treatment. }\end{array}$ & $\begin{array}{l}\text { Those who reapplied to the gender } \\
\text { clinic in adolescence reported more } \\
\text { body dissatisfaction in comparison } \\
\text { to those who did not reapply }\end{array}$ \\
\hline Vocks et al. & 2009 & $\begin{array}{l}\text { Germany, Austria } \\
\text { and Switzerland }\end{array}$ & $\begin{array}{l}\mathrm{N}=356(\mathrm{n}=88 \text { trans } \\
\text { females, } \mathrm{n}=43 \text { trans } \\
\text { males, } \mathrm{n}=72 \text { eating } \\
\text { disorders, } \mathrm{n}=163 \text { controls })\end{array}$ & $\begin{array}{l}\text { Eating Disorder Examination } \\
\text { Questionnaire } \\
\text { EDI-2 } \\
\text { Body Checking Questionnaire } \\
\text { Drive for Muscularity Scale }\end{array}$ & None & $\begin{array}{l}57 \% \text { of trans females on CHT } \\
\text { and } 18 \% \text { had SRS } \\
61 \% \text { of trans males on CHT } \\
\text { and } 33 \% \text { had SRS }\end{array}$ & $\begin{array}{l}\text { Trans participants > body } \\
\text { dissatisfaction and eating disorder } \\
\text { behaviour and attitudes in } \\
\text { comparison to controls but these } \\
\text { levels were not as high as the eating } \\
\text { disorder patients }\end{array}$ \\
\hline $\begin{array}{l}\text { Wiseman \& } \\
\text { Moradi }\end{array}$ & 2010 & USA & $\begin{array}{l}\mathrm{N}=231 \text { ( } 2 \% \text { transgender } \\
\text { and } 97 \% \text { as cisgender })\end{array}$ & $\begin{array}{l}\text { Objectified body consciousness } \\
\text { scale } \\
\text { EAT-26 }\end{array}$ & None & Information not reported & $\begin{array}{l}\text { Eating problems and body image } \\
\text { concerns rarely experienced }\end{array}$ \\
\hline Witcomb et al. & 2015 & UK & $\begin{array}{l}\mathrm{N}=600(\mathrm{n}=200 \\
\text { transsexuals, } \mathrm{n}=200 \text { eating } \\
\text { disorder patients and } \\
\mathrm{n}=200 \text { controls) }\end{array}$ & $\begin{array}{l}\text { EDI-2 } \\
\text { The Hamburg Body Drawing } \\
\text { Scale }\end{array}$ & ICD & $\begin{array}{l}\text { Trans were at the assessment } \\
\text { stage }\end{array}$ & $\begin{array}{l}\text { Trans individuals do not have } \\
\text { clinically significant eating } \\
\text { disorders, but they may exhibit > } \\
\text { eating disorder symptomology } \\
\text { compared to controls }\end{array}$ \\
\hline $\begin{array}{l}\text { Wolfradt \& } \\
\text { Neumann }\end{array}$ & 2001 & Germany & $\begin{array}{l}\mathrm{N}=90 \text { ( } \mathrm{n}=30 \text { trans females, } \\
\mathrm{n}=60 \text { controls) }\end{array}$ & The Body-Image Questionnaire & None & SRS and voice operation & SRS > body image satisfaction. \\
\hline
\end{tabular}

Note: EAT (Eating Attitudes Test), EDI (Eating Disorder Inventory), BUT (Body Uneasiness Test), BCS (Body Cathexis Sclae), BIS (Body Image Scale), SRS (Sexual-reassignment Surgery), GnRHa (Gonadotrophin-releasing hormone agonists), CHT (Cross-sex Hormone Therapy), DSM (Diagnostic Statistical Manual), ICD (Internationally Classification of Diseases). 
Body dissatisfaction and disordered eating in trans people 28

Screening stage

Eligibility stage

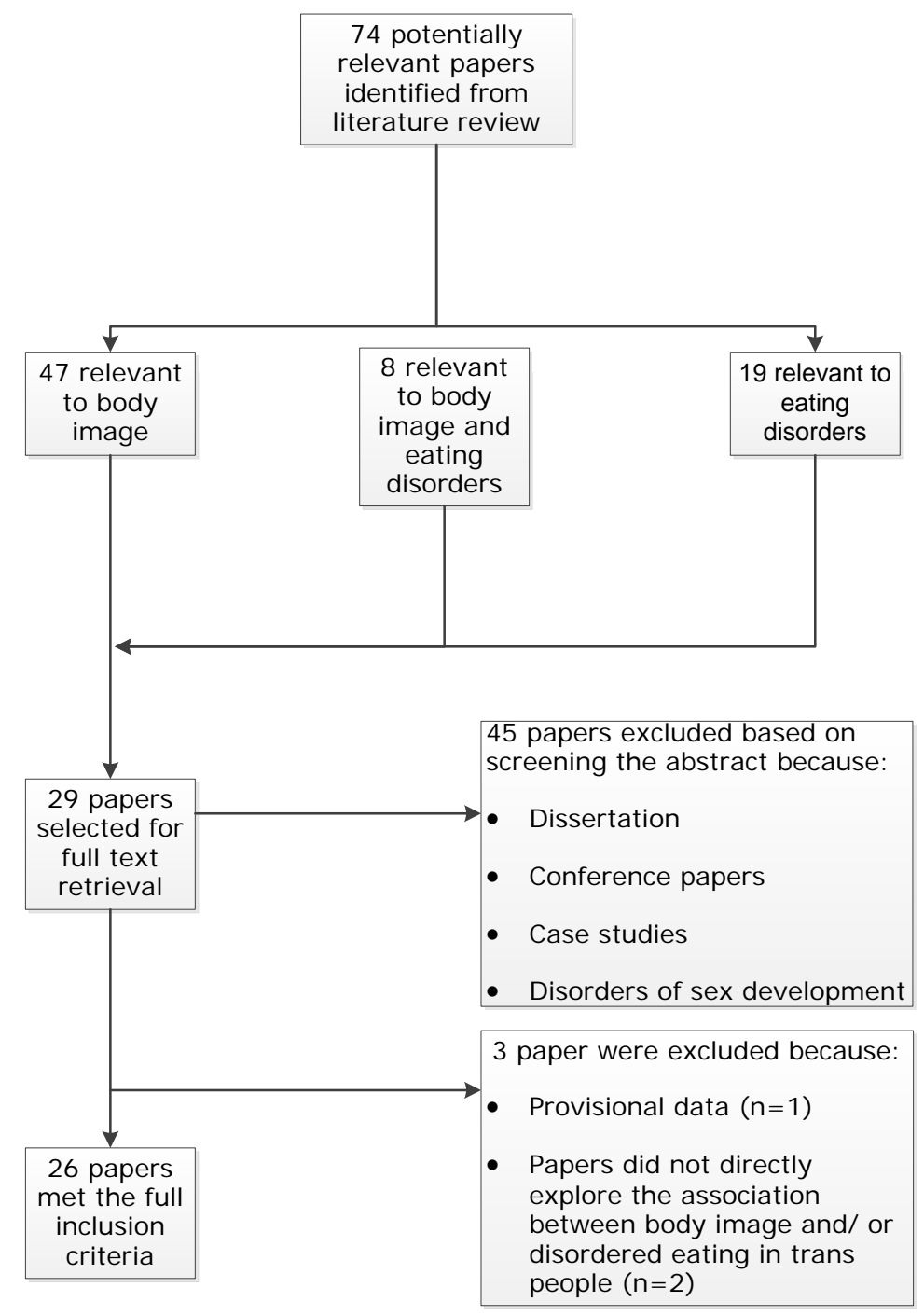

Figure 1: The process of identifying eligible studies for inclusion within this review 